\title{
Risk factors analysis: screening of extended- spectrum- $\beta$-lactamase producing Gram-negative isolates of burn infections from tertiary care hospital Lahore, Pakistan
}

Muhammad Hayat Haider

University of the Punjab

Noor Ul Ain

University of the Punjab

Shahida Hussain

University of the Punjab

Samyyia Abrar

University of the Punjab

Amina Asif

general hospital

Farhan Rasheed

Allama Iqbal Medical College

Muhammad Umair Shareef

Jinnah Hospital

Ramza Mushtaq

Jinnah Hospital

Muhammad Nauman Ali

Jinnah Hospital

saba riaz ( $\square$ saba.mmg@pu.edu.pk)

University of the Punjab https://orcid.org/0000-0002-6630-5689

Research article

Keywords: Risk factors, ESBL, burn infections, Pakistan, TBSA.

Posted Date: May 14th, 2019

DOl: https://doi.org/10.21203/rs.2.9481/v1

License: (c) (i) This work is licensed under a Creative Commons Attribution 4.0 International License. Read Full License 
Page $2 / 18$ 


\section{Abstract}

Background Burnt patients are highly susceptible to invasion of multidrug resistant strains after the skin damage. The main objective of this study was to estimate the frequency of ESBLs producing Gramnegative in post-burn infections and its correlation with different risk factors (age, gender, socio-economic status, burns etiology etc.) Methods The descriptive case-series study was conducted at Jinnah Hospital Lahore's Burn and Reconstructive Surgery Centre (JB \& RSC) and the Department of Microbiology and Molecular Genetics (MMG), University of the Punjab, Lahore. The clinical specimens of wound swabs, biopsy, and blood were collected from 300 patients during 12th August, 2017 to 12th August 2018. The cephalosporins resistant Gram-negative isolates were further analyzed. The clinical history of burnt patients was recorded which included the age, gender, socio-economic status, residence, occupation, hospital stay, wards, burn degree, total burnt surface area (TBSA\%), etiology of burn and other factors. CLSI guidelines 2017 were followed for the antimicrobial susceptibility testing (AST) and ESBLs screening. Results Pseudomonas spp. were the most-frequently isolated $49.33 \%(n=74)$ followed by $22.67 \%(n=34)$ Klebsiella spp., and $20.00 \%(n=30)$ Acinetobacter spp., strains. Pseudomonas spp., were the most frequently isolated from burnt specimens 70 (46.67\%) having a significant correlation $(x 2=24.11, p<0.001)$. Community acquired infections were observed in $50.70 \%(n=76)$ and nosocomial infections in $49.30 \%(n=74)$ patients. Burnt people having the age of $\leq 29$ years were found to be significantly associated with the MDR infections $(x 2=24.96, p=0.003)$. Low socio-economic status, longer hospitalization and all other risk factors had non-significant correlation ( $p>0.05)$. A large fraction of the isolates $86.00 \%(n=129)$ were not confirmed as ESBLs producers by phenotypic screening. Conclusion It has been concluded that Gram-negative MDR strains are rapidly causing infections in burnt patients and need to be properly alleviated. The high frequency of multidrug resistant Pseudomonas spp., was associated with the burn infections. The patients belonging to young age were significantly found to be infected by MDR strain after burns.

\section{Background}

Burn injuries are caused by chemical, electrical, and thermal exposures to the skin and underlying epidermis, dermis and tissues [1]. Burns are classified by calculating the percentage of total burnt area of the body[2]. The extent of skin damage determines the first, second, and third degree burn [3]. First degree burns affect the surface; second degree burns involve broken skin layers; and third degree burns deeply affect underlying tissues [4]. Burn cases annually account for 0.3 million demises worldwide [5]. The frequency is in USA the $0.2 \%$, a little high in Turkey $2.3 \%$, and in India $3.6 \%$ cases per thousand people annually [6]. Post-burn infections caused by multidrug resistant (MDR) bacterial strains account for $75 \%$ of mortality rate [7]. Bacterial pathogens responsible for post-burn infections include multidrug resistant (MDR) strains of Gram-negative bacteria (GNB)[8].These include mostly the Acinetobacter baumannii, Escherichia coli, Klebsiella pneumoniae, Proteus spp., Pseudomonas aeruginosa, Staphylococcus aureus, and Streptococcus pyogenes[9]. Sepsis is the ultimate consequence of burnt skin invasion by MDR 
bacterial strains which begin to proliferate within 48 hours [4]. It has been estimated that $73 \%$ of postburn mortalities happen due to septic shock [10].

Community acquired and nosocomial infectious agents are transmitted to burnt patients by different sources [4]. Operative procedures include catheterization, dialysis, mechanical ventilation and surgery. Health care workers (HCWs) are also found to be associated with transmission of pathogens by fomites or hands [11]. The demographic parameters found to be associated with the multidrug resistance development include age, gender, residence (rural/urban), occupation, literacy, socioeconomic status, and comorbidities. Empirical or home based antibiotics intake, ineffective diagnosis, and inappropriate antibiotic prescription are also the major contributing factors $[12,13]$. Duration of therapy and stay at hospital also increase the risk of acquiring infection by multidrug resistant (MDR) Gram negative ESBLs producing bacteria [14]. Horizontal gene transfer leads to the accumulation of antimicrobial resistance genes resulting into the emergence of MDRs [15]. Multidrug resistant strains of $A$. baumannii are involved in adjournment of wound healing process. These strains get invaded into the blood circulatory system and cause transplant damage and septic shock [16].

Survival of the fittest is the likely phenomenon which eliminates the susceptible bacteria from the pool and allows flourishing the MDRs [17]. Department of Centres for Disease Control and Prevention has reported that annually around 23000 patients in the United States die out of two million people got infected by MDRs $[18,19]$. There is an estimated loss of 1.5 billion euros annually in the Europe which is an outcome of antimicrobial resistance [20]. It has been estimated that these outcomes may lead to worldwide 10 billion deaths annually by 2050. National Institute of Health in Pakistan has implemented the World Health Organization (WHO) recommendations of antimicrobial surveillance 2015 as the National Action Plan to overcome the resistance [21]. Pakistan Institute of Medical Sciences (PIMS), Islamabad harbors more proportions of Gram-negative bacteria in surgical wards and burn unit [22]. According to the best of our knowledge, we are lacking the understanding of risk factors associated with post-burn infections in our society, therefore this study was initiated.There is urgent need to assemble the countrywide statistics on antimicrobial resistance and to initiate the infection control and antibiotic stewardship plans. The main objective of this study is to obtain a clear picture of antimicrobial susceptibility and resistance in bacterial pathogens and to categorize the risk factors associated with the emergence of MDRs isolated from burnt patients.

\section{Methods}

\section{Study design}

The study has been designed according to the prospective investigation principles to identify the risk factors associated with the emergence of multi-drug resistant Gram negative bacterial pathogens. The descriptive case series study has been conducted in the Jinnah Burn and Reconstructive Surgery Centre (JB\&RSC), Department of Microbiology and Molecular Genetics (MMG) University of the Punjab in collaboration with Citi Lab and Research Centre Lahore, Pakistan. The study was approved by the Ethical 
Review Board (ERB) of Allama Iqbal Medical College (AIMC) \& Jinnah Hospital Lahore in its $40^{\text {th }}$ meeting held on $12^{\text {th }}$ August, 2017. The clinical specimens with no-growth after 24-48 hours incubation were excluded from this study. The specimens with multiple isolates and showing sensitivity against cephalosporins were also excluded from further analysis. Mono-bacterial cultures of cephalosporins resistant Gram-negative bacterial strains were included further studies.

\section{Sampling and data collection}

Purposive non-probability method was for the sampling from indoor/outdoor burn wards and intensive care unit (ICU). Accordingly, 300 clinical specimens including wound swabs, biopsy, and blood were collected within duration of one year from $12^{\text {th }}$ August, 2017 to $12^{\text {th }}$ August 2018. The demographic information regarding the age, gender, socio-economic status, residence, occupation, hospital stay, wards, burn degree, total burnt surface area (TBSA\%), etiology of burns and other factors have been collected by a designing a data form.

\section{Bacterial isolation and identification}

The specimens were immediately moved to the Microbiology Laboratory (JB\&RSC) for clinical processing. The aerobic culturing by differential and selective media was performed for the isolation of bacteria. The specimen enrichment was performed in trypticase soy broth (TSB) and after overnight incubation at $37^{\circ} \mathrm{C}$ the Blood agar and MacConkey's agar were inoculated. Microscopy, colony morphology, and biochemical characterization was performed by API-20E kit system (Bio-Merieux, France) [23].

\section{Antibiotics Susceptibility Testing (AST)}

Antibiotic susceptibility testing of bacterial isolates was performed on Mueller Hinton agar by Kirby Bauer's disc diffusion method according to Clinical Laboratory Standards Institute (CLSI) guidelines 2017 [9]. Antibiotics tested were including (OXOID) penicillins [(piperacillin (PIP $100 \mu \mathrm{g})$, (amoxycillinclavulanate (AMC $40 \mu \mathrm{g}$ ), ampicillin-sulbactam (SAM 10/10 $\mu \mathrm{g}$ ), piperacillin-tazobactam (TZP $110 \mu \mathrm{g}$ )], monobactams (aztreonam (ATM $30 \mu \mathrm{g}$ )], cephalosporins [(ceftazidime (CAZ $30 \mu \mathrm{g}$ ), cephradine (CE 30 $\mu \mathrm{g}$ ), cefixime (CFM $30 \mu \mathrm{g}$ ), cefoperazone (CFP $30 \mu \mathrm{g}$ ), cefoperazone-sulbactam (SCF $110 \mu \mathrm{g}$ ), cefotetan $(\mathrm{CN} 100 \mu \mathrm{g})$, cefprozil (CPR $30 \mu \mathrm{g})$, ceftriaxone (CRO $30 \mu \mathrm{g})$, cefotaxime (CTX $30 \mu \mathrm{g})$, cefuroxime (CXM $30 \mu \mathrm{g})$, cefoxitin (FOX $30 \mu \mathrm{g})$, cefazoiln (KZ $30 \mu \mathrm{g})$ ], carbapenems [(doripenem (DOR $10 \mu \mathrm{g})$, ertapenem $($ ETP $10 \mu \mathrm{g})$, imipenem (IMI $10 \mu \mathrm{g})$, meropenem (MEM $10 \mu \mathrm{g})$ ], aminoglycosides [(amikacin (AK $30 \mu \mathrm{g})$, gentamicin (GEN $30 \mu \mathrm{g})$, tobramycin (TOB $30 \mu \mathrm{g})$ ], glycylcycline [(tigecycline (TGC $15 \mu \mathrm{g})$ ], macrolide [(erythromycin (ERY $15 \mu \mathrm{g})$ ], peptides [(polymyxin B (PB $10 \mu \mathrm{g})$, colistin (PE $10 \mu \mathrm{g})$ ], fluoroquinolones [(ciprofloxacin (CIP $10 \mu \mathrm{g})$, (levofloxacin (LEV $5 \mu \mathrm{g})$, norfloxacin (NOR $10 \mu \mathrm{g})$, ofloxacin (OFL $10 \mu \mathrm{g})$ ], quinolones [(nalidixic acid (NAL $30 \mu \mathrm{g})$ ], and tetracyclines [(doxycycline (DC $30 \mu \mathrm{g})$, tetracycline (TET 30 $\mu \mathrm{g})][24]$.

\section{Phenotypic screening of extended spectrum $\beta$-lactamases (ESBLs)}


Double disk synergism test (DDST) as a gold-standard phenotypic method and combination disc test (CDT) as confirmatory test for ESBLs. The tests were performed on Mueller-Hinton's (MH) agar by Kirby Bauer's disk diffusion method as previously reported by Chen et al.,[13].

\section{Statistical analysis}

The statistical analysis was executed by Statistical Package for Social Sciences (SPSS) version 23. The demographic characteristics such as age, gender, residence, and occupation of the patients have been represented as the percentage value in the descriptive analysis. The age and total burnt surface area (TBSA \%) were the continuous variables which have been analyzed statistically to highlight the standard deviation (mean $\pm S D$ ) values. The association of risk factors with the type of infection (MDR/Non-MDR) was calculated as chi-square and probability values. The $p$-value $<0.05$ was taken as significant.

\section{Results}

\section{Frequency distribution of burnt patients and risk factors}

A total of 300 clinical specimens were collected from burnt patients during 12 months duration from August 2017 to August 2018. No growth specimens, colonization, cephalosporins sensitive and Grampositive strains were excluded from the analysis. The remaining specimens included wound swabs 92.00 $\%(n=138)$, blood $6.70 \%(n=10)$, and tissue biopsy $1.30 \%(n=2)$ for further analysis. These specimens were taken from $72.00 \%$ of the males $(n=108)$ and $28.00 \%$ of females $(n=42)$. The age of the patients ranged from 4 to 85 years (Mean of age $=28$ years, $\pm 15.65 \mathrm{SD}$ ). Burn injuries were more frequent in the young age groups having the age of $\leq 29$ years. Patients belonging to the urban areas $62.00 \%(n=93)$ and the low socio-economic background $80.00 \%(n=120)$ were found to be the victims of burn injuries. There was lower proportion of patients $32.70 \%(n=49)$ having the smoking history.

Higher frequency of the burn victims was admitted as indoor patients $71.30 \%(n=107)$ as compared to outdoor patients $28.70 \%(n=43)$. Outdoor patients were discharged within one day of examination and treatment. The indoor patients were admitted $38.7 \%(n=58)$ to general ward, $26 \%(n=39)$ to intensive care unit (ICU), and $06.67 \%(n=10)$ to plastic surgery ward (PSW). A large number of patients $76 \%$ $(n=114)$ were discharged within one week of admission and treatment. Slightly higher proportion of community-acquired infection was observed in $50.70 \%(n=76)$ as compared to nosocomial infections in $49.30 \%(n=74)$ patients. The comorbidities were also present in $39.30 \%(n=59)$ patients.

The mean value of TBSA was $30.13 \%, 14.62 \pm$ SD. Higher number of patients was observed with the second degree burns $50.00 \%(n=75)$. First degree burns were operated by stitching and bandages $26 \%$ $(n=39)$. Second and third degree burns were gone through different invasive procedures such as subcutaneous surgery in $41.30 \%(n=62)$ and percutaneous surgery in $10.70 \%(n=16)$ patients. The occupational burn injuries were reported in only $28.70 \%(n=43)$ patients. Burn etiology was also assessed and the flames $52.70 \%(n=79)$ were the most common source amongst the burn victims. Scald burns and contact burns were equally present amongst $21.40 \%(n=32)$ of patients (Figure-1). 


\section{Frequency distribution of bacterial isolates and antimicrobial susceptibility testing (AST)}

Pseudomonas spp., was the frequently detected bacterial pathogen $49.30 \%(\mathrm{n}=74)$ followed by Klebsiella spp., $22.70 \%(n=34)$, Acinetobacter spp., $20 \%(n=30)$, and Proteus spp., $8 \%(n=12)$. Majority of these isolates was lactose non-fermenters (LNFs) $73.30 \%(n=110)$. Above $80 \%$ of bacterial strains were resistant to ceftazidime (CAZ $30 \mu \mathrm{g}$ ), cefotaxime (CTX $30 \mu \mathrm{g}$ ), doripenem (DOR $10 \mu \mathrm{g}$ ), and ertapenem (ETP $10 \mu \mathrm{g}$ ). More than 90\% strains were resistant to gentamicin (GEN $30 \mu \mathrm{g}$ ), tobramycin (TOB $30 \mu \mathrm{g}$ ), and tetracyclines. The resistance against amikacin (AMK $30 \mu \mathrm{g}$ ), imipenem (IMI $10 \mu \mathrm{g}$ ), and meropenem (MEM $10 \mu \mathrm{g}$ ) was in between $60-70 \%$. Polymyxin B and E showed a promising susceptibility pattern with $25.33 \%(n=38)$ and $44.67 \%(n=67)$ resistance respectively (Figure-2).

\section{Frequency distribution of MDR infections and risk factors association}

MDR isolates were detected in $83.30 \%(n=125)$ burnt patients. Most frequent Gram-negative MDR was Pseudomonas spp. isolated from $46.67 \%(n=70)$ patients $\left(x^{2}=24.11, p<0.001\right)$. The age factor was found to be significantly associated $\left(x^{2}=24.95, p=0.003\right)$ with the higher frequency of infections caused by multi-drug resistant Gram-negative bacterial pathogens. The age group of $20-29$ years included $40.00 \%(n=60)$ patients of which $90.00 \%(n=54)$ were infected by MDRs. The non-significant difference was found amongst all other risk factors $(p>0.05)$ including gender, burn degree, TBSA \%, burn etiology, occupation, residence, comorbidities, hospital stay, and surgical procedures amongst the patients. The higher frequency of MDRs was detected in $84.30 \%(n=91)$ females. The indoor patients were found to be more exposed to the MDR strains $84.10(n=90)$. Second degree burn patients were frequently associated with ESBLs $86.70 \%(n=65)$ as compared to first and third degree burns (Table-1).

\section{Phenotypic screening of ESBLs}

Screening by DDST was effective only to detect $16.00 \%(n=24)$ ESBLs producers. The confirmation was made by CDT and only $14 \%(n=21)$ ESBLs strains were detected. Pseudomonas spp. was the mainly detected as ESBL producer in $6.67 \%(n=10)$ patients detected by DDST. This number was further reduced to $3.33 \%(n=5)$ when confirmed by CDT (Table-2).

\section{Discussion}

Post-burn infections are a major cause of mortality due to severe types of infections. The compromised immune system of burnt patients makes them susceptible to microbial infections by bacterial or fungal pathogens $[15,25]$. Here, burnt patients were observed with a mean age of $28 \pm 15.65$ years while Melake et al., reported $15 \pm 17.60$ years mean age [4]. Males (72.00\%) were found to be more exposed to burns than females $(28.00 \%)$. Saaiq et al., also reported the high frequency of post-burn infections in in males (53.68\%) than females (46.31\%) [22]. The higher frequency $62.00 \%$ of burnt patients belonged to urban areas, while Anvarinejad et al., reported $74.50 \%$ cases from rural areas [26]. $80.00 \%$ of the patients belonged to low socio-economic status. Chamania et al., also reported a significant association between the low socio-economic status of the patients with MDR infections [27]. The negative correlation of 
smoking with MDR infections coincides with Melake et al., findings [4]. The reason behind the significant correlation of burn injuries with higher frequency in males is that they are more exposed to the environment that harbors burn sources [28]. People with low-socio-economic status are observed working in industries located in urban areas [29].

Higher frequency of burnt patients was observed with $50.00 \%$ second and $22.00 \%$ third degree burns. Vural et al., also reported higher number of patients with the second degree burns [30]. The reason behind the low frequency of first degree burns is the home-based treatment by commercially available tonics and topical ointments. Second and third degree burns involve broken skin layers and underlying tissues, therefore their treatment is very difficult at home [4]. Burn etiology also varies in different studies. Flames were the most common cause of burns in $52.70 \%$ patients, as was reported by Saaiq et al., where 76.00 $\%$ patients were exposed to flames[22]. Anvarinejad et al., reported $93.00 \%$ of burn injuries caused by chemical exposure [26].

The extent of skin damage (TBSA \%) was less than $20 \%$ in majority of our patients ( $66.00 \%$ ) revealing non-significant association with MDR infections. Findings reported by Fadeyibi et al., differ from our study where a strong correlation was found between the extent of skin damage and MDR infections [31]. The occupation of the patients was also not significantly associated with the MDR infections, as nonoccupational incidents were reported in $71.30 \%$ patients. Melake et al., also reported that there was not any significant association between the occupational injuries and MDR infections [4].

Although a large number of patients $71.30 \%$ were admitted as indoor but the hospital stay of $76.00 \%$ patients was less than one week, revealing non-significant correlation between longer hospital and MDR infections. Fadeyibi et al., have reported strong association between MDR infections and longer hospital stay where $50.00 \%$ burnt patients were monitored for more than three weeks. It means that longer hospitalization is significantly associated with the MDRs infections[31]. Here, $26.00 \%$ burnt patients were admitted in the ICU for the treatment revealing non-significant association with MDRs. Leseva et al., reported a positive correlation between the MDR infections and the number of patients admitted in intensive care units (ICUs) [8].

Mono-bacterial Gram-negative cultures were analyzed only and the isolates with more than one bacterial species were excluded from further analysis. Saaiq et al., also reported $93 \%$ mono-bacterial infections frequently caused by Gram-negative bacteria [22]. The reason behind analyzing the single species isolates is to lessen the probability of contamination as a single bacterium in-vitro is enough to cause infection [32]. Two decades ago Pruitt et al., reported that post-burn infections are mostly categorized as nosocomial infections as they are frequently caused by hospital-acquired pathogens [33]. Leseva et al., also reported only the nosocomial infections in $10.6 \%$ per thousand burnt patients during the year 2011, but the community-acquired infections were not assessed [8]. Our findings differ from these studies as the community-acquired infections (50.70 \%) were more frequent than the nosocomial infections (49.30 $\%$ ) in burnt patients. The reason behind the increase in community-acquired infections is the empirical use of antibiotics and previous exposures of longer antibiotic-therapy[34]. 
Gram-negative bacterial pathogens are ubiquitous and also known for their abundance in hospitals and surgical settings [35]. Most of the Gram-negative bacteria adhere to the surgical instruments and make sure resistance against desiccation [36]. The association between the surgical procedures and MDR infections was not statistically significant while Vinodkumar et al., reported positive correlation [37]. Comorbidities were already present in only $39.33 \%$ patients, although Melake et al., reported a strong correlation of MDR infections with $28.60 \%$ patients having comorbidities [4].

Pseudomonasaeruginosa has been frequently isolated from the burnt patients in the recent studies [22, $38,39]$. We also observed thatPseudomonas spp., was the most abundantly isolated bacterial pathogen from $49.33 \%$ burnt patients. The frequency of MDR infections was also higher including $83.33 \%$ of patients. There were $68.70 \%$ isolates with antimicrobial resistance against the imipenem (IMI). Polymyxin E (colistin) was effective against MDR strains with $55.30 \%$ sensitivity. Mohamed has also reported similar results where Pseudomonas spp., was the most prevalent pathogen among all of the clinical isolates (49\%). The prevalence of MDR Gram negative isolates was $60 \%$ where most of the isolates were resistant to imipenem (65\%). The colistin was the most promising antibiotic with the $84 \%$ sensitivity [40]. $60 \%$ of the isolates were resistant to imipenem (IMI), and ertapenem (ERT) in a study reported from Riyadh, Saudi Arabia [41].

We observed that only $16.00 \%$ of isolates were detected as ESBLs producers by double disk synergy test (DDST) and only $14.00 \%$ were confirmed by combination disk test (CDT). These findings differ from the study reported by Hassan et al., where $99.00 \%$ of the isolates were detected as ESBLs producers by CDT and $68.70 \%$ by DDST [42]. Therefore it is highly recommended that the ESBLs detection should be accomplished by highly advanced molecular techniques.

The infections in burnt patients emerge due to invasion of pathogens or by colonization of the opportunistic bacterial strains [31]. Decolonization strategies may prove helpful in minimizing the infections by highly pathogenic MDR bacterial strains [43]. The clinical presentation of infections in burnt patients is very different from others. Erythema, swelling, progressive cellulitis of burn wounds, and sepsis are the clinical manifestations of burn wounds associated infections[44]. Therefore it is necessary to regularly monitor burnt patients and rapidly diagnose and control the spread of infectious agents among burnt patients [45].

\section{Conclusions}

The community acquired and nosocomial infections are becoming problematic in our society.Gramnegative MDR strains are rapidly causing infections in burnt patients and need to be properly alleviated. The high frequency of multidrug resistant Pseudomonas spp., was associated with the burn infections. The patients belonging to young age were significantly found to be infected by MDR strain after burns. Pakistan is facing a lot of problems and challenges in healthcare. The facilities which are necessary for the treatment of post-burn infected patients are not sufficient in hospitals. There are a few functional burn units, but the diagnostic and treatment options are limited. There have been a few studies 
conducted on the epidemiology of post-burn infections in Pakistan. These studies have been mostly conducted in tertiary care hospitals. Most of the studies are limited to bacteriological profiles and their antibiotic susceptibility patterns. It is necessary to provide the advanced diagnostic tools for ESBLs producers because phenotypic tests are not very helpful. The rapid diagnosis and identification of causative pathogens can ensure the correct antibiotics prescription by physicians. Timely and appropriate wound management and antibiotics prescription can make a huge difference by lessening the multidrug resistance.

\section{Abbreviations}

CLSI: Clinical Laboratory Standards Institute; ERB; Ethical Review Board; CDST: Combination disc test; DDST: Double disc synergy test; ESBL: Extended-spectrum $\beta$-Lactamase; HCW: Health-care workers; JB\&RSC: Jinnah Burn Unit and Reconstructive Surgery Centre; MDR: Multidrug-resistant; MMG: Department of Microbiology and Molecular Genetics; TBSA: Total Burnt Surface Area.

\section{Declarations}

This work is part of Ph.D thesis of Mr. Muhammad Hayat Haider.

\section{Ethical approval and consent to participate}

This study has been approved by the Ethical Review Board (ERB) of Allama Iqbal Medical College (AIMC) \& Jinnah Hospital Lahore in its $40^{\text {th }}$ meeting held on $12^{\text {th }}$ August, 2017.

Written informed consent was obtained from all participants. Written informed consent was from the parents/guardianare children (under 16 years of age) with the help of burn centre staff and $\mathrm{MHH}$..

\section{Consent for publication}

Not applicable

\section{Availability of data and materials}

The data sets analyzed during the current study are available from the corresponding author.

\section{Competing interests}

Authors declare that they have no competing interests.

\section{Funding}

No funding was received for this study.

\section{Author's contributions}


$\mathrm{MHH}, \mathrm{SR}, \mathrm{AA}$, and FR conceived and designed the study, analyzed and interpreted the data. MHH, NUA, and SA performed the laboratory work. MHH, MUS, RM, and MNA collected the clinical specimens and data of the patients. SH performed statistical analysis and critically reviewed the manuscript. $\mathrm{MHH}$ prepared and finalized the manuscript.

\section{Author details}

${ }^{1}$ Department of Microbiology and Molecular GeneticsQuaid-i-Azam Campus, University of the Punjab, Lahore-54590; Pakistan. ${ }^{2}$ Post-graduate Medical Institute of Ameerudin Medical College, General Hospital, Lahore, Pakistan; ${ }^{3}$ Allama Iqbal Medical College (AIMC), Lahore, Pakistan; ${ }^{4}$ Jinnah Burn \& Reconstructive Surgery Centre, Jinnah Hospital, Lahore, Pakistan. Citilab and Research centre Lahore, 525- A Faisal Town Lahore, Pakistan.

\section{Acknowledgements}

We would like to acknowledge the Pathology Laboratory of Burn Unit and Reconstructive Surgery Centre (JB\&RSC), Jinnah Hospital Lahore for providing us the clinical isolates of burnt patients. We would also like to acknowledge Allama Iqbal Medical College (AIMC), Lahore for helping in demographic data collection. We are thankful to Dr. Muhammad Faisal, CEO of Citi Lab and Research Centre Lahore for providing us the guidelines to design this clinical study. We also highly acknowledge the contributions of Mr. Muhammad Umar Farooq, Biostatistician \& In charge, IT of Institute of Public Health (IPH), Lahore for the statistical analysis. This study has been partially presented in $59^{\text {th }}$ Annual International Laboratory Medicine Congress and Exhibition (LMCE) 2018, organized by Korean Society of Laboratory Medicine on November $1^{\text {st }}-3^{\text {rd }}, 2018$ in the Seoul, South Korea.

\section{References}

1. Abbassi MS, Torres C, Achour W, Vinué L, Sáenz Y, Costa D, Bouchami O, Hassen AB. Genetic characterisation of CTX-M-15-producing Klebsiellapneumoniae and Escherichiacoli strains isolated from stem cell transplant patients in Tunisia. Int J Antimicrob Agents. 2008;32(4):308-314.

2. Mahadevan SV, Garmel GM. An introduction to clinical emergency medicine: guide for practitioners in the emergency department: Cambridge University Press; 2005.

3. Alebachew T, Yismaw G, Derabe A, Sisay Z.Staphylococcusaureus burn wound infection among patients attending Yekatit 12 hospital burn unit, Addis Ababa, Ethiopia. Ethiop J Health Sci.2012;22(3).

4. Melake NA, Eissa NA, Keshk TF, Sleem AS. Prevalence of multidrug-resistant bacteria isolated from patients with burn infection. Menoufia Med J.2015;28(3):677.

5. Öncül O, Öksüz S, Acar A, Ülkür E, Turhan V, Uygur F, Ulçay A, Erdem H, Özyurt M, Görenek L. Nosocomial infection characteristics in a burn intensive care unit: analysis of an eleven-year active surveillance. Burns.2014;40(5):835-841. 
6. Weber DJ, van Duin D, DiBiase LM, Hultman CS, Jones SW, Lachiewicz AM, Sickbert-Bennett EE, Brooks RH, Cairns BA, Rutala WA. Healthcare-associated infections among patients in a large burn intensive care unit: incidence and pathogens, 2008-2012. Control Hosp Epidemiol.2014;35(10):1304-1306.

7. Church D, Elsayed S, Reid O, Winston B, Lindsay R. Burn wound infections. Clin Microbiol Rev.2006;19(2):403-434.

8. Leseva M, Arguirova M, Nashev D, Zamfirova E, Hadzhyiski O. Nosocomial infections in burn patients: etiology, antimicrobial resistance, means to control. Ann Burns Fire Disasters.2013;26(1):5.

9. Richcane A, Samuel CT, Pius A, Enoch F, Thomas KG, Poku OSP. Bacteriological profile of burn wound isolates in a burns center of a tertiary hospital. J Acute Dis.2017;6(4):181.

10. Sewunet T, Demissie Y, Mihret A, Abebe T. Bacterial profile and antimicrobial susceptibility pattern of isolates among burn patients at Yekatit 12 hospital burn center, Addis Ababa, Ethiopia. Ethiop J Health Sci.2013;23(3):209-216.

11. Kumar SH, De AS, Baveja SM, Gore MA. Prevalence and risk factors of metallo $\beta$-lactamase producing Pseudomonasaeruginosa and Acinetobacter species in burns and surgical wards in a tertiary care hospital. J Lab Physicians.2012;4(1):39.

12. Islam M, Yusuf MA, Chowdhury M, Hossain MA: ESBL producing gram negative aerobic bacteria isolated from burn wound infection with their antibiogram in dhaka. JSci Found.2012, 10(2):17287855 .

13. Chen Z, Niu H, Chen G, Li M, Li M, Zhou Y. Prevalence of ESBLs-producing Pseudomonasaeruginosa isolates from different wards in a Chinese teaching hospital. J Sci Found.2015;8(10):19400.

14. Lachiewicz AM, Hauck CG, Weber DJ, Cairns BA, Van Duin D. Bacterial infections after burn injuries: impact of multidrug resistance. Clin Exp Med.2017;65(12):2130-2136.

15. Sánchez M, Herruzo R, Marbán A, Araujo P, Asensio MJ, Leyva F, Casado C, García-de-Lorenzo A. Risk factors for outbreaks of multidrug-resistant Klebsiellapneumoniae in critical burn patients. J Burn Care Res.2012;33(3):386-392.

16. Selcuk CT, Bozkurt M, Kuvat SV, Tekin A, Tekin R, Kapi E. An evaluation of burn infections caused by multidrug resistant A.baumannii and the treatment approach. J Current Surg.2011;1(1):7-11.

17. Prestinaci F, Pezzotti P, Pantosti A. Antimicrobial resistance: a global multifaceted phenomenon. Pathog Glob Health.2015;109(7):309-318.

18. Control CfD, Prevention. World Health Day: media fact sheet. Antimicrobial resistance: no action today, no cure tomorrow. In.: April7; 2011.

19. Paphitou NI. Antimicrobial resistance: action to combat the rising microbial challenges. Int $J$ Antimicrob Agents.2013;42:S25-S28.

20. Roca I, Akova M, Baquero F, Carlet J, Cavaleri M, Coenen S, Cohen J, Findlay D, Gyssens I, Heure O. The global threat of antimicrobial resistance: science for intervention. New Microbes New Infect.2015;6:22-29. 
21. Saleem Z, Hassali MA. Travellers take heed: Outbreak of extensively drug resistant (XDR) typhoid fever in Pakistan and a warning from the US CDC. Travel Med Infect Dis.2018.

22. Saaiq M, Ahmad S, Zaib MS. Burn wound infections and antibiotic susceptibility patterns at Pakistan Institute of Medical Sciences, Islamabad, Pakistan. World J Plast Surg.2015;4(1):9.

23. Iskender NA, Algur OF, Aksu Y, Saral A. Isolation, identification and characterization of biotechnologically important bacteria from microflora of Dryocosmuskuriphilus Yasumatsu (Hymenoptera: Cynipidae). Biotechnol Biotechnol Equip.2017;31(3):505-510.

24. Magiorakos AP, Srinivasan A, Carey R, Carmeli Y, Falagas M, Giske C, Harbarth S, Hindler J, Kahlmeter G, Olsson-Liljequist B. Multidrug-resistant, extensively drug-resistant and pandrug-resistant bacteria: an international expert proposal for interim standard definitions for acquired resistance. Clin Microbiol Infect.2012;18(3):268-281.

25. Jewo P, Duru F, Osinubi A, Fadeyibi I, Faduyile F, Benebo A. Histological changes and testicular dysfunction in severely burned rats. Macedonian J Med Sci.2011;4(3):227-233.

26. Anvarinejad M, Japoni A, Rafaatpour N, Mardaneh J, Abbasi P, Shahidi MA, Dehyadegari MA, Alipour E. Burn patients infected with metallo-beta-lactamase-producing Pseudomonasaeruginosa: multidrug-resistant strains. Arch Trauma Res.2014; 3(2).

27. Chamania S, Hemvani N, Joshi S. Burn wound infection: Current problem and unmet needs. Indian J Burns.2012;20(1):18.

28. Tang K, Jian L, Qin Z, Zhenjiang L, Gomez M, Beveridge M. Characteristics of burn patients at a major burn center in Shanghai. Burns.2006;32(8):1037-1043.

29. Edelman LS. Social and economic factors associated with the risk of burn injury. Burns.2007;33(8):958-965.

30. Vural MK, Altoparlak U, Celebi D, Akcay MN. Comparison of surface swab and quantitative biopsy cultures dependent on isolated microorganisms from burn wounds. Eurasian J Med.2013;45(1):34.

31. Fadeyibi IO, Raji MA, Ibrahim NA, Ugburo AO, Ademiluyi S. Bacteriology of infected burn wounds in the burn wards of a teaching hospital in Southwest Nigeria. Burns.2013;39(1):168-173.

32. Lagier J-C, Edouard S, Pagnier I, Mediannikov O, Drancourt M, Raoult D. Current and past strategies for bacterial culture in clinical microbiology. Clin Microbiol Rev.2015; 28(1):208-236.

33. Pruitt Jr BA, McManus AT, Kim SH, Goodwin CW. Burn wound infections: current status. World J Surg.1998;22(2):135-145.

34. Krobot K, Yin D, Zhang Q, Sen S, Altendorf-Hofmann A, Scheele J, Sendt W. Effect of inappropriate initial empiric antibiotic therapy on outcome of patients with community-acquired intra-abdominal infections requiring surgery. Europ J Clin Microbiol InfectDis.2004;23(9):682-687.

35. Naas T, Poirel L, Nordmann P. Minor extended-spectrum $\beta$-lactamases. Clin Microbiol Infect.2008, 14:42-52.

36. Cardoso T, Ribeiro O, Aragão IC, Costa-Pereira A, Sarmento AE. Additional risk factors for infection by multidrug-resistant pathogens in healthcare-associated infection: a large cohort study. BMC Infect 
Dis. 2012;12(1):375.

37. Bandekar N, Vinodkumar C. Beta lactamases mediated resistance amongst gram negative bacilli in Burn Infection. 2003.

38. Singh NP, Rani M, Gupta K, Sagar T, Kaur IR. Changing trends in antimicrobial susceptibility pattern of bacterial isolates in a burn unit. Burns.2017;43(5):1083-1087.

39. Jena J, Debata NK, Sahoo RK, Subudhi E. Phylogenetic study of metallo- $\beta$-lactamase producing multidrug resistant Pseudomonasaeruginosa isolates from burn patients. Burns.2015;41(8):17581763.

40. Mohamed $\mathrm{H}$. One year prevalence of critically ill burn wound bacterial infections in surgical ICU in Egypt: Retrospective study. EgypJ Anaesth.2016;32(3):431-434.

41. Al-Agamy MH, Aljallal A, Radwan HH, Shibl AM. Characterization of carbapenemases, ESBLs, and plasmid-mediated quinolone determinants in carbapenem-insensitive Escherichiacoli and Klebsiellapneumoniae in Riyadh hospitals. J Infect Pub Health.2018;11(1):64-68.

42. Ejaz H. Detection of extended-spectrum $\beta$-lactamases in Klebsiellapneumoniae: Comparison of phenotypic characterization methods. Pak J Med Sci.2013;29(3):768.

43. Exner M, Bhattacharya S, Christiansen B, Gebel J, Goroncy-Bermes P, Hartemann P, Heeg P, Ilschner C, Kramer A, Larson E. Antibiotic resistance: What is so special about multidrug-resistant Gram-negative bacteria? GMS Hyg Infect Control.2017;12.

44. Norbury W, Herndon DN, Tanksley J, Jeschke MG, Finnerty CC, Society SSCotSI. Infection in burns. Surglnfect.2016;17(2):250-255.

45. Lee AS, Macedo-Vinas M, François P, Renzi G, Schrenzel J, Vernaz N, Pittet D, Harbarth S. Impact of combined low-level mupirocin and genotypic chlorhexidine resistance on persistent methicillinresistant Staphylococcusaureus carriage after decolonization therapy: a case-control study. Clin Infect Dis.2011;52(12):1422-1430.

\section{Tables}

Table 1: Distribution of risk factors associated with MDR and non-MDRs infections in burnt patients. 


\begin{tabular}{|c|c|c|c|c|c|c|}
\hline Risk factors & Divisions & $\begin{array}{c}\text { MDR } \\
\text { infections }\end{array}$ & $\begin{array}{l}\text { Non-MDR } \\
\text { infections }\end{array}$ & $\begin{array}{c}\text { Total } \\
(\mathrm{n}=150)\end{array}$ & $x^{2}$ & $\mathrm{p}$-value \\
\hline \multirow[t]{7}{*}{ Age (years) } & $<10$ & $8(80.0 \%)$ & $2(20.0 \%)$ & $10(6.67 \%)$ & \multirow[t]{7}{*}{24.96} & \multirow[t]{7}{*}{0.003} \\
\hline & $10-19$ & $27(96.4 \%)$ & $1(3.6 \%)$ & $28(18.67 \%)$ & & \\
\hline & $20-29$ & $54(90.0 \%)$ & $6(10.0 \%)$ & $60(40.00 \%)$ & & \\
\hline & $30-39$ & $12(60.0 \%)$ & $8(40.0 \%)$ & $20(13.33 \%)$ & & \\
\hline & $40-49$ & $13(100.0 \%)$ & $0(0.0 \%)$ & $13(8.67 \%)$ & & \\
\hline & $50-59$ & $5(62.5 \%)$ & $3(37.5 \%)$ & $8(5.33 \%)$ & & \\
\hline & $>60$ & $6(54.5 \%)$ & $5(45.5 \%)$ & $11(7.33 \%)$ & & \\
\hline \multirow[t]{2}{*}{ Gender } & Male & $91(84.3 \%)$ & $17(15.7 \%)$ & $108(72.00 \%)$ & \multirow[t]{2}{*}{0.238} & \multirow[t]{2}{*}{0.626} \\
\hline & Female & $34(81.0 \%)$ & $8(19.0 \%)$ & $42(28.00 \%)$ & & \\
\hline \multirow[t]{2}{*}{ Residence } & Rural & $48(84.2 \%)$ & $9(15.8 \%)$ & $57(38.00 \%)$ & \multirow[t]{2}{*}{0.051} & \multirow[t]{2}{*}{0.821} \\
\hline & Urban & $77(82.8 \%)$ & $16(17.2 \%)$ & $93(62.00 \%)$ & & \\
\hline \multirow[t]{2}{*}{ Indoor/outdoor } & Indoor & $90(84.1 \%)$ & $17(15.9 \%)$ & $107(71.33 \%)$ & \multirow[t]{2}{*}{0.163} & \multirow[t]{2}{*}{0.686} \\
\hline & Outdoor & $35(81.4 \%)$ & $8(18.6 \%)$ & $43(28.67 \%)$ & & \\
\hline \multirow[t]{4}{*}{ Burn wards } & General ward & $50(86.2 \%)$ & $8(13.8 \%)$ & $58(38.67 \%)$ & \multirow[t]{4}{*}{0.664} & \multirow[t]{4}{*}{0.882} \\
\hline & ICU & $32(82.1 \%)$ & $7(17.9 \%)$ & $39(26.00 \%)$ & & \\
\hline & OPD & $36(83.72 \%)$ & $7(16.28 \%)$ & $43(28.67 \%)$ & & \\
\hline & Plastic surgery ward & $7(70 \%)$ & $3(30 \%)$ & $10(6.67 \%)$ & & \\
\hline \multirow{7}{*}{$\begin{array}{l}\text { Hospital stay } \\
\text { (days) }\end{array}$} & $<3$ & $78(85.7 \%)$ & $13(14.3 \%)$ & $91(60.67 \%)$ & \multirow[t]{7}{*}{8.14} & \multirow[t]{7}{*}{0.456} \\
\hline & $3-7$ & $18(78.3 \%)$ & $5(21.7 \%)$ & $23(15.33 \%)$ & & \\
\hline & $8-14$ & 17(89.5\%) & $2(10.5 \%)$ & $19(12.67 \%)$ & & \\
\hline & $15-21$ & $4(50.0 \%)$ & $4(50.0 \%)$ & $8(5.33 \%)$ & & \\
\hline & $22-28$ & $6(85.7 \%)$ & $1(14.3 \%)$ & $7(4.67 \%)$ & & \\
\hline & $29-35$ & $1(100.0 \%)$ & $0(0.0 \%)$ & $1(0.67 \%)$ & & \\
\hline & $>35$ & $1(100.0 \%)$ & $0(0.0 \%)$ & $1(0.67 \%)$ & & \\
\hline \multirow[t]{7}{*}{ TBSA (\%) } & $<10$ & $47(81.0 \%)$ & $11(19.0 \%)$ & $58(38.67 \%)$ & \multirow[t]{7}{*}{2.55} & \multirow[t]{7}{*}{0.798} \\
\hline & $10-19$ & $36(87.8 \%)$ & $5(12.2 \%)$ & $41(27.33 \%)$ & & \\
\hline & $20-29$ & $19(79.2 \%)$ & $5(20.8 \%)$ & $24(16.00 \%)$ & & \\
\hline & $30-39$ & $14(87.5 \%)$ & $2(12.5 \%)$ & $16(10.67 \%)$ & & \\
\hline & $40-49$ & $4(80.0 \%)$ & $1(20.0 \%)$ & $5(3.33 \%)$ & & \\
\hline & $50-59$ & $2(66.7 \%)$ & $1(33.3 \%)$ & $3(2.00 \%)$ & & \\
\hline & $>60$ & $3(100.0 \%)$ & $0(0.0 \%)$ & $3(2.00 \%)$ & & \\
\hline \multirow[t]{3}{*}{ Burn degree } & First & $33(78.6 \%)$ & $9(21.4 \%)$ & $42(28.00 \%)$ & \multirow[t]{3}{*}{1.34} & 0.512 \\
\hline & Second & $65(86.7 \%)$ & $10(13.3 \%)$ & $75(50.00 \%)$ & & \\
\hline & Third & $27(81.8 \%)$ & $6(18.2 \%)$ & $33(22.00 \%)$ & & \\
\hline Burn etiology & Acid burn & $3(75.0 \%)$ & $1(25.0 \%)$ & $4(2.67 \%)$ & 3.92 & 0.552 \\
\hline & Chemical burn & $9(100.0 \%)$ & $0(0.0 \%)$ & $9(6.00 \%)$ & & \\
\hline & Contact burn & $14(87.5 \%)$ & $2(12.5 \%)$ & $16(10.67 \%)$ & & \\
\hline & Electric burn & $11(84.6 \%)$ & $2(15.4 \%)$ & $13(8.67 \%)$ & & \\
\hline & Flame burn & $63(79.7 \%)$ & $16(20.3 \%)$ & $79(52.67 \%)$ & & \\
\hline & Frictional burn & $3(100.0 \%)$ & $0(0.0 \%)$ & $3(2.00 \%)$ & & \\
\hline & Oil burn & $9(90.0 \%)$ & $1(10.0 \%)$ & $10(6.67 \%)$ & & \\
\hline & Scald burn & $13(81.3 \%)$ & $3(18.8 \%)$ & $16(10.67 \%)$ & & \\
\hline Injury type & Non-occupational & $88(82.2 \%)$ & $19(17.8 \%)$ & $107(71.33 \%)$ & 0.319 & 0.572 \\
\hline & Occupational & $37(86.0 \%)$ & $6(14.0 \%)$ & $43(28.67 \%)$ & & \\
\hline Socio-economic & High & $25(83.3 \%)$ & $5(16.7 \%)$ & $30(20.00 \%)$ & 0.000 & 1.000 \\
\hline
\end{tabular}

Page 15/18 


\begin{tabular}{|c|c|c|c|c|c|c|}
\hline status & Low & $100(83.3 \%)$ & $20(16.7 \%)$ & $120(80.00 \%)$ & & \\
\hline \multirow[t]{2}{*}{ Smoking history } & Non-smokers & $86(85.1 \%)$ & $15(14.9 \%)$ & $101(67.33 \%)$ & \multirow[t]{2}{*}{0.733} & \multirow[t]{2}{*}{0.392} \\
\hline & Smokers & $39(79.6 \%)$ & $10(20.4 \%)$ & $49(32.67 \%)$ & & \\
\hline \multirow[t]{5}{*}{ Surgical procedure } & Catheterization & $21(84.0 \%)$ & $4(16.0 \%)$ & $25(16.67 \%)$ & \multirow{5}{*}{1.51} & \multirow{5}{*}{0.830} \\
\hline & $\begin{array}{c}\text { Percutaneous } \\
\text { surgery }\end{array}$ & $13(81.3 \%)$ & $3(18.8 \%)$ & $16(10.67 \%)$ & & \\
\hline & Plastic surgery & $6(75.0 \%)$ & $2(25.0 \%)$ & $8(5.33 \%)$ & & \\
\hline & Stitching & $31(79.5 \%)$ & $8(20.5 \%)$ & $39(26.00 \%)$ & & \\
\hline & $\begin{array}{c}\text { Subcutaneous } \\
\text { surgery }\end{array}$ & $54(87.1 \%)$ & $8(12.9 \%)$ & $62(41.33 \%)$ & & \\
\hline \multirow[t]{2}{*}{ Co-morbidities } & Absent & $78(85.7 \%)$ & $13(14.3 \%)$ & $91(60.67 \%)$ & \multirow[t]{2}{*}{0.944} & \multirow[t]{2}{*}{0.331} \\
\hline & Present & $47(79.7 \%)$ & $12(20.3 \%)$ & $59(39.33 \%)$ & & \\
\hline \multirow[t]{2}{*}{ Type of infection } & Community acquired & $64(84.2 \%)$ & $12(15.8 \%)$ & $76(50.67 \%)$ & \multirow[t]{2}{*}{0.085} & \multirow[t]{2}{*}{0.770} \\
\hline & Nosocomial & $61(82.4 \%)$ & $13(17.6 \%)$ & $74(49.33 \%)$ & & \\
\hline \multirow{4}{*}{$\begin{array}{c}\text { Most Abundant } \\
\text { strain }\end{array}$} & Acinetobacter spp. & $25(83.3 \%)$ & $5(16.7 \%)$ & $30(20.00 \%)$ & \multirow[t]{4}{*}{24.11} & \multirow[t]{4}{*}{$<0.001$} \\
\hline & Klebsiella spp. & $25(73.5 \%)$ & $9(26.5 \%)$ & $34(22.67 \%)$ & & \\
\hline & Proteus spp. & $5(41.7 \%)$ & $7(58.3 \%)$ & $12(8.00 \%)$ & & \\
\hline & Pseudomonas spp. & $70(94.6 \%)$ & $4(5.4 \%)$ & $74(49.33 \%)$ & & \\
\hline \multirow[t]{3}{*}{ Specimen type } & Blood & $10(100.0 \%)$ & $0(0.0 \%)$ & $10(6.67 \%)$ & \multirow[t]{3}{*}{2.609} & \multirow[t]{3}{*}{0.1021} \\
\hline & Tissue biopsy & $2(100.0 \%)$ & $0(0.0 \%)$ & $2(1.33 \%)$ & & \\
\hline & Wound swab & 113(81.9\%) & $25(18.1 \%)$ & 138(92.0\%) & & \\
\hline
\end{tabular}

Table 2: Distribution of ESBLs positive isolates and comparison of DDST and CDT efficacy.

\begin{tabular}{|c|c|c|c|c|}
\hline \multirow{2}{*}{ Bacterial strains } & \multicolumn{2}{|c|}{ DDST results (\%) } & \multicolumn{2}{c|}{ CDT results (\%) } \\
\cline { 2 - 5 } & ESBL positive & Not-determined & ESBL positive & Not-determined \\
\hline Pseudomonas spp. & $8(5.33 \%)$ & $66(44.00 \%)$ & $10(6.67 \%)$ & $64(42.67 \%)$ \\
\hline Klebsiella spp. & $7(4.67 \%)$ & $27(18.00 \%)$ & $5(3.33 \%)$ & $29(19.33 \%)$ \\
\hline Acinetobacter spp. & $7(4.67 \%)$ & $23(15.33 \%)$ & $4(2.67 \%)$ & $26(17.33 \%)$ \\
\hline Proteus spp. & $2(1.33 \%)$ & $10(6.67 \%)$ & $2(1.33 \%)$ & $10(6.67 \%)$ \\
\hline Total (n=150) & $\mathbf{2 4 ( 1 6 . 0 0 \% )}$ & $\mathbf{1 2 6 ( 8 4 . 0 0 \% )}$ & $\mathbf{2 1 ( 1 4 . 0 0 \% )}$ & $\mathbf{1 2 9 ( 8 6 . 0 0 \% )}$ \\
\hline
\end{tabular}

\section{Figures}




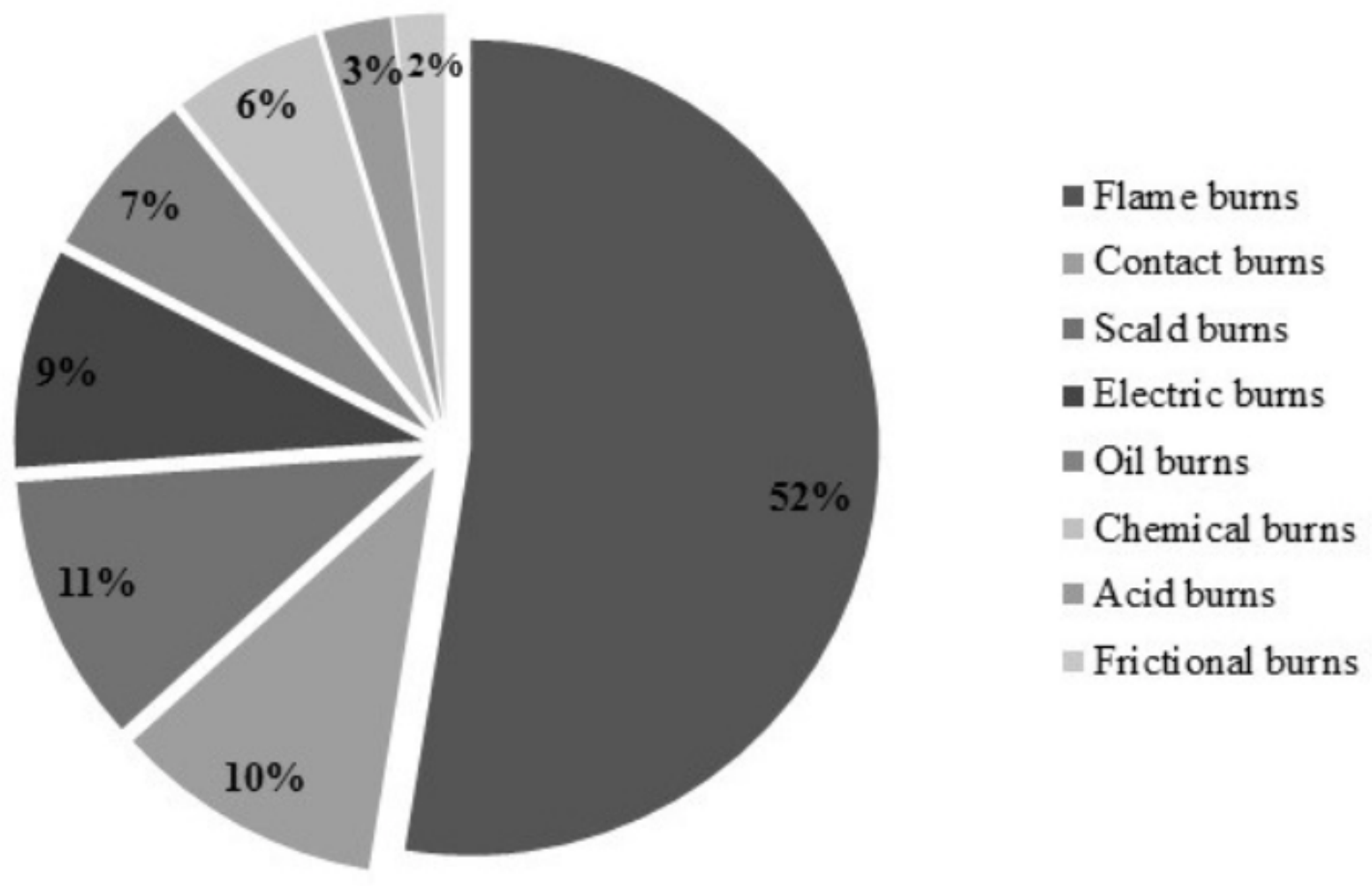

Figure 1

Distribution of burnt patients exposed to different types of burn sources.

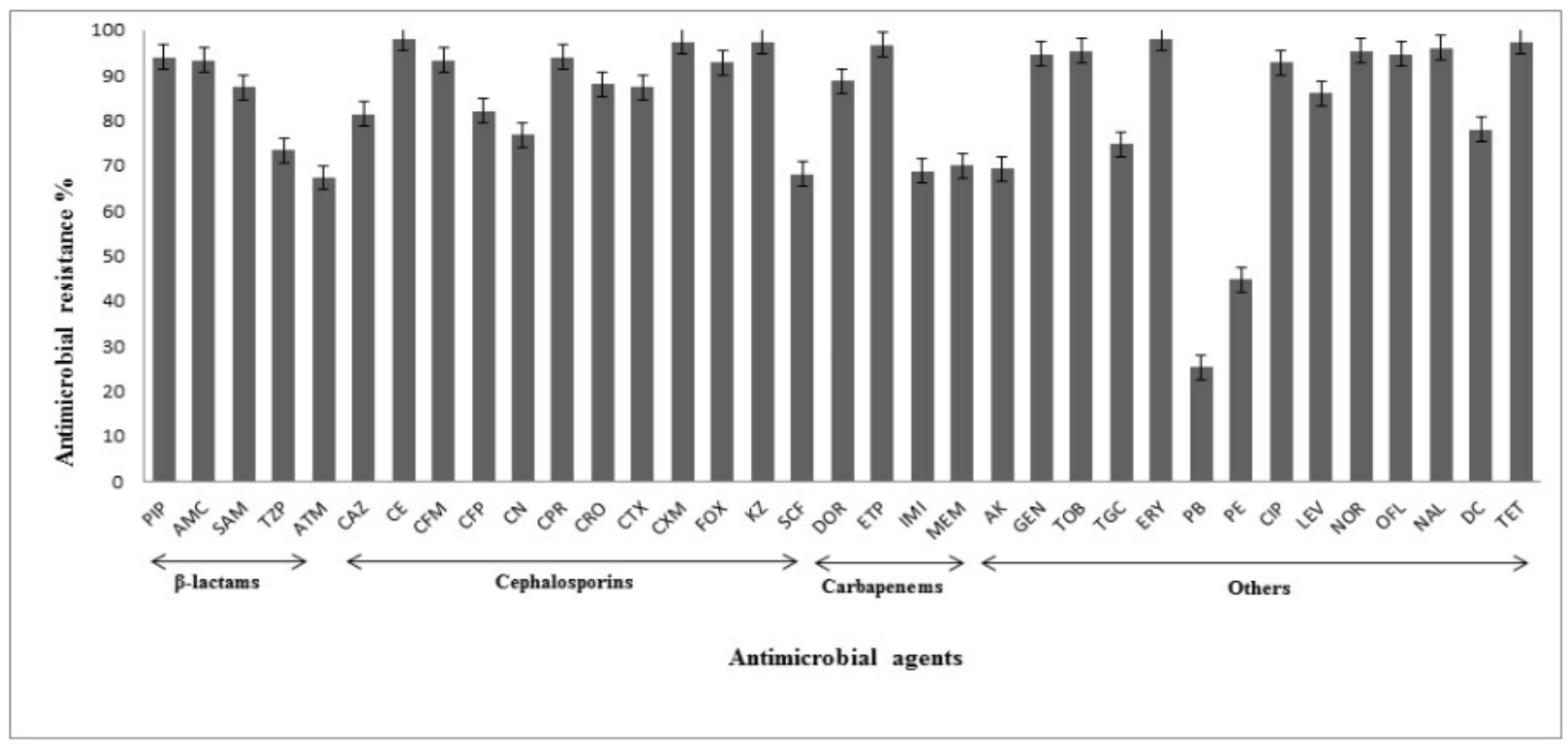

Figure 2 
Distribution of ESBLs positive isolates and comparison of DDST and CDT efficacy. 